\section{RANCIÈRE E O DANO NA POLÍTICA -}

\author{
a reconfiguração do espaço do povo e a \\ igualdade para os sem-voz
}

\author{
Michelly Alves Teixeira \\ Graduanda em Filosofia - UnB
}

\begin{abstract}
Resumo:Este trabalho é parte de uma pesquisa iniciada pelo PIBIC, na área de Filosofia Política, uma pesquisa que tem como objeto algumas teses do autor francês contemporâneo Jacques Rancière. Do autor tomamos sua tese de que, na posição de espectador, agimos sobretudo como espectadores do mundo. Essa primeira parte trata da formação da comunidade no período antigo formulada na obra $O$ desentendimento, e veremos como em seu percurso o povo [demos] recupera o reconhecimento de seu papel dentro da comunidade. $\mathrm{Na}$ segunda parte, retomamos o papel da democracia e o conceito de comunidade política como um grupo de indivíduos governados por um poder, uma minoria de oligarcas e algumas implicações da democracia representativa no âmbito social contemporâneo. Na terceira, valendo-nos do texto $O$ ódio à democracia, acompanharemos como a comunidade política passa por oscilações, tendo-se a passagem para a democracia como representação por fio condutor.
\end{abstract}

Palavras-chave: Rancière; democracia; comunidade política; dano; conflito

Résumé: Ce travail fait partie d'une recherche initiée par PIBIC dans le domaine de la philosophie politique, une recherche qui a comme objet certaines revendications de l'auteur français contemporain Jacques Rancière. De l'auteur nous prenonssa thèse dans le quel, chez une position de l'observateur, nous agissons sourtout comme les téléspectateurs du monde. Cette première partie traite de la formation de la communauté dans la période antique formulées dans le travail "La mésentente", et de voir comment dans son voyage le peuple [démos] récupère la reconnaissance de leur rôle au sein de la communauté. Dans la deuxième partie, nous revenons au rôle de la démocratie et le concept de communauté politique en tant que groupe d'individus régis par un pouvoir, une minorité d'oligarques, et des implications de la démocratie représentative dans le contexte social contemporain. Dans le troisième, en se fondant sur le texte "La haine de la démocratie", nous allons suivre que la communauté politique subit des fluctuations, et la transition vers la démocratie comme une représentation par clé de lecture.

Mots-clés: Rancière; la démocratie; communauté politique; dommages; conflit

\section{I}

Nessa primeira parte veremos como a pólis instaura os sem-parcela, a partir do percurso do povo ao retomar a comunidade em nome de um litígio, às voltas com o dano responsável pela fundamentação da política, um litígio em que o povo busca reconhecimento de seu papel dentro da comunidade, e o dano é a recusa desse reconhecimento. O povo só volta a fazer parte da comunidade (fazer parte, diga-se, ser ativo nas decisões políticas) em nome de um litígio ou dano.

Jacques Rancière, ao trazer a estrutura de sua argumentação na obra $O$ desentendimento, nos deixa uma curta conclusão que resume a proposta de nosso artigo: os clássicos nos ensinam que a política não se ocupa dos vínculos entre os indivíduos, nem das relações entre os indivíduos e a comunidade, ela seria da alçada de uma contagem das "partes" da comunidade, contagem que é sempre uma falsa contagem, uma dupla contagem ou um erro na contagem (cf. RANCIÈRE, 1996, p. 21).

A partir desse erro na contagem das "partes" da comunidade, o autor nos leva à definição da política como a atividade que tem por princípio a igualdade, e esse princípio transforma-se em repartição das parcelas ${ }^{1}$, ou seja, a política começaria onde se pararia de equilibrar lucros e perdas, onde se tentaria repartir as parcelas do comum e os títulos para se obter essas parcelas.

\footnotetext{
${ }^{1}$ Parcela. No original, part (o termo francês partie foi traduzido como parte). Designa a parte que cabe a alguém numa divisão ou distribuição, o quinhão que é dado a uma pessoa ou que legitimamente deveria ser seu. Jogam com essa palavra, igualmente, partido (francês partie), parceiro (francês partenaire), divisão (francês partage) - nota do revisor técnico.
} 
Para uma boa explicação do que seja essa repartição das parcelas e os títulos para obtêlas, o autor nos remete a Aristóteles quando define o homem dotado de palavra (logos), capaz de dispor dos sentimentos de bem e mal, justo e injusto e apto a constituir uma politicidade que se perfaz na família e na pólis. Aristóteles separa essa parcela em títulos (axiai) e define três que dão direito à comunidade: a riqueza dos poucos (oligoi), a virtude ou a excelência (areté), que dá seu nome aos melhores (aristói), e a liberdade que pertence ao povo (demos). Mesmo havendo um desequilíbrio nessa construção da oligarquia dos ricos, a aristocracia das pessoas de bem ou a democracia do povo, essa combinação proporciona o bem comum, traz um valor para a comunidade e esse valor lhe dá o direito de deter uma parte do poder comum.

Para expor o problema fundamental na contagem das partes, o autor faz a seguinte indagação: "O que é, em contrapartida, a liberdade trazida pelas pessoas do povo à comunidade? E em que lhes é própria?" (RANCIÈRE, 1996, p. 22), essa liberdade do demos não determinável, mas facticidade. Mesmo após a abolição da escravidão, a impossibilidade dos oligoi de reduzir seus devedores a escravos tornou a liberdade que seria propriedade positiva do povo, como parte da comunidade, apenas mera aparência. Isso já pressupõe uma determinada ideia de política que carrega em seu cerne a relação de duas palavras-chave, igualdade e a liberdade. Para melhor exemplificar, e para responder à segunda indagação do autor, a sabedoria "liberal" já descreve os efeitos de uma igualdade artificial, e os seus clássicos, nas origens da política moderna, já encontram uma liberdade vazia que coloca limites à igualdade. Portanto, essa liberdade até impede a oligarquia de governar pelo jogo dos lucros e das dívidas, mas prova que oligarquia e riqueza são sinônimos de dominação.

A liberdade, também vista como virtude comum, torna-se qualidade daqueles que, sem méritos, nem riqueza, identificam-se por homonímia com o todo da comunidade. E ao identificar-se como o todo da comunidade, o povo, mesmo sendo uma massa indiferenciada, sem nenhum titulo e sem virtudes, vê-se pertencente da mesma liberdade que aqueles que possuem títulos.

Ao se apropriar dessa qualidade comum, prossegue o autor, o povo traz a comunidade, o litígio. Assim, essa massa de homens sem propriedades se identifica na comunidade em nome de um dano ${ }^{2}$ e é em nome desse dano que lhe é causado pelas outras partes, pelos outros títulos que o povo se identifica com o todo da comunidade. Afinal, conclui o autor, quem não tem parcela - os pobres da Antiguidade, o terceiro estado ou o proletariado moderno - não pode ter outra parcela a não ser nada ou tudo.

É mediante a existência dessa parcela dos sem parcela e desse litígio que afeta a contagem das partes que a comunidade existe enquanto comunidade política. O povo é a classe do dano que causa dano à comunidade, e para grande escândalo dos demais, o demos, esse amontoado de pessoas de nada, torna-se a comunidade que fala e decide na Assembleia.

2 Dano. No original, tort. Indica o dano causado a alguém, com sentido não apenas físico, mas, sobretudo, jurídico. Avoir tort é estar errado, não ter razão; faire tort a alguém é fazer-lhe mal. 


\section{II}

O cenário explicitado por Rancière com o princípio da voz e representatividade popular nos remete, em novo percurso, à ideia de representatividade parlamentar e ao problema da adequação do exercício político, das forças presentes nesse âmbito e ao paradoxo em torno de instituições representativas.

De saída, apresenta Rancière, mesmo Platão, sendo antidemocrata, enxerga de modo justo os fundamentos da política e da democracia: para ele o erro de cálculo presente na democracia é em si o erro de cálculo fundador da política. Mesmo que exista um demos que fala e decide na Assembleia, em sua composição predomina uma desigualdade e essa igualdade impossível arruina toda a dedução das partes e títulos que constituem a pólis. Aristóteles, ao partir para a mesma crítica, definiria, no livro IV da Constituição de Atenas, que a pólis tem apenas duas partes: os ricos e os pobres (Aristóteles, Politica, IV, 1294 a 17-19, apud RANCIÈRE, 1996, p. 26).

Ao enfatizar-nos o tema da desigualdade, o autor propõe reconhecer que foram os antigos, muito mais que os modernos, que identificaram no princípio da política a luta dos pobres e dos ricos. Essa luta teria sido reconhecida, pensa Rancière, tendo-se por base a interrupção da ordem natural da dominação pela instituição dessa parcela dos sem parcela. Fora dessa instituição não haveria política, conclui, existiria apenas a ordem da dominação ou a desordem da revolta.

Por ser o todo da política que define o comum da comunidade, a instituição da parcela dos sem parcela é baseado num dano. Tendo por princípio a desigualdade e a luta entre ricos e pobres, conclui-se que o povo que constitui essa democracia não é realmente o povo, mas sim os pobres, que sendo parte do reino da ausência de qualidade, são o litígio e o dano.

Portanto, o partido dos pobres representa a própria política como instituição da parcela dos sem parcela, enquanto o partido dos ricos, da Atenas do século $\mathrm{V}$ até os governos de hoje, terá dito apenas uma única coisa, que define exatamente a negação da política: "não há parcela dos sem parcela" (RANCIÈRE, 1996, p. 29, grifo do autor). Desde os liberais do século XIX, ela é vista apenas como chefes e subordinados, pessoas de bem e pessoas de nada, elites e multidões. Na contemporaneidade esse quadro de oposições se reporia como maiorias e minorias sociais, grupos de interesses e partes das quais devemos fazer parceiros. Pode-se inferir, portanto, que a proposta segue a mesma: não há parcela dos sem parcela, somente parcela das partes.

Com esse recorte, fica claro que a guerra entre pobres e ricos é a guerra sobre a existência da política. O litígio da contagem dos pobres como povo, e do povo como comunidade é o litígio devido ao qual há política. Por meio desse litigio é que surge a política, quando a ordem natural dos reis, pastores, senhores de guerra é interrompida por uma liberdade que atualizaria a igualdade última na qual se assentaria toda a ordem social. $\mathrm{Na}$ medida em que a ordem na sociedade surge porque uns mandam e outros obedecem, para obedecer é necessário a compreensão dessa ordem e para compreender é preciso obedecer. Portanto, existe política porque há o logos que ordena e confere o direito e o ordenar.

$\mathrm{O}$ autor afirma que essa igualdade acabaria por corroer toda a ordem natural. Porém os inferiores obedecem na quase 
totalidade dos casos e a ordem social é remetida a sua contingência última, raciocínio que culmina com a sentença: "a desigualdade só é possível pela igualdade" (RANCIÈRE, 1996, p. 31). A política, sob esse figurino, passa a existir quando a lógica da dominação enquanto uma lógica natural do poder se impõe, a macular o efeito da igualdade. Por isso mesmo se pode dizer, conclui Rancière, que, nesse processo, não existe política, já que sua ação depende da dominação que macula a igualdade. Se não está fundada na igualdade, o processo de dominação mostra-se atrelado a outras maquinarias do poder, que provém do exercício da majestade, da divindade, do comando dos exércitos ou da gestão de interesses.

Nos termos dessa leitura, a política que acaba entrando em cena é a movida pelo que lhe é estranho e que ocasiona, tudo somado, a suspensão da condição de possibilidade da política mesma: a pressuposição da igualdade de qualquer pessoa com qualquer pessoa, ou seja, a paradoxal efetividade da pura contingência de toda ordem.

Os clássicos buscariam determinar essa igualdade à custa de se esquivar de seu enunciado, mediante o recurso à enunciação da liberdade deles com base em um contrário que seria a escravidão: o escravo teria a capacidade de compreender o logos sem ter a capacidade exercê-lo, o logos. Tratar-se-ia de uma igualdade que pode ser colocada sem que afete a política: a naturalidade contingente da liberdade do homem do povo e a naturalidade da escravidão podem se dividir, sem se remeter à contingência final da própria igualdade. Um exemplo seria, lembra Rancière, quando Platão faz com que o escravo de Menon descubra a regra da duplicação do quadrado e o fato dele chegar tão bem quanto Sócrates nessa operação e isso faria com que ele participe da mesma inteligência, mas Platão não extraiu disso a possibilidade de se estabelecer qualquer forma de inclusão comunitária.

A política, defende o autor francês, toma seu papel quando a contingência igualitária interrompe, como "liberdade" do povo, a ordem natural das dominações, quando essa interrupção produz uma divisão da sociedade em partes que não são "verdadeiras", quando, a partir de uma instituição, o todo se iguala, seja em nome de uma "propriedade" que não lhe é própria, seja de um "comum" que é a comunidade do litígio. Desenha-se assim o figurino, prossegue o autor, do dano que define a instituição da política e a instituição da luta de classes.

Nos termos desse percurso, a luta de classes é a própria política e não o seu motor secreto ou a verdade escondida por trás de suas aparências. Ela é a política tal como a encontram os que querem fundar a comunidade com base em sua arkhé. A política existe porque institui as classes como diferentes de si mesmas e institui o litígio entre elas. $\mathrm{O}$ proletariado moderno, bem como o demos ateniense, une-se em nome do titulo da igualdade, através do qual todas as classes se dividem e a política existe. A introdução desse incomensurável no seio das distribuições dos corpos falantes não rompe somente a igualdade dos lucros e das perdas, mas arruina o projeto da pólis baseada em sua arkhé da comunidade.

\section{III}

Passemos à parte final da leitura aqui proposta, e volte-se o olhar à democracia, resumida em três aspectos. Primeiro, a democracia é o tipo de comunidade definida 
pela existência de uma esfera de aparência especifica do povo (RANCIÈRE, 2014, p.102), aparência aqui com o sentido de introdução, no campo da experiência, de um visível que modifica o regime do visível.

Segundo, os ocupantes dessa esfera de aparência possuem um particular, um povo que não consiste em nenhum grupo social, mas "sobre-impõe" à dedução das parcelas da sociedade a efetividade de uma parcela dos sem-parcela. Aqui o povo tem um duplo corpo e essa dualidade é a do corpo social e de um corpo que vem remover toda identificação social (RANCIÈRE, 2014, p.103).

Terceiro aspecto da democracia, esse lugar de aparência predominante no povo é o lugar de condução do conflito/litígio. O litígio político diferencia-se de conflitos de interesses entre partes constituídas da população, já que é um conflito sobre a contagem das partes.

A democracia o autor toma como ponto de partida é a que nasce em Atenas. Lá, a participação dos cidadãos na política, mediante distribuição de cargos por meio do sorteio aleatório, é um governo de qualquer um. A vinculação do demos - o poder ou o governo do demos - desenvolve um sintoma negativo em torno da pólis. O resultado desse desagrado gira em torno de uma minoria oligárquica e o essencial é fundamentar essa separação entre democracia direta e representativa e a sua implicância no social.

Temos uma primeira manifestação de ódio ao conceito de democracia lá na Antiguidade, graças aos que viam a ruína de toda ordem legítima no inominável governo da multidão. Continuou sendo razão de ódio para os que acreditavam que o poder pertencia somente aos que já eram beneficiados por ele desde o nascimento ou eleito por competências. Assim como é odiada pelos que fazem da lei divina a única forma de poder e legitimidade fundante de comunidades.

Sendo assim, afirma Rancière, a palavra democracia não designa formas de sociedade de governo. A "sociedade democrática" é apenas uma fantasia com a função de sustentar um principio do bom governo. Não existe governo democrático propriamente dito. Os governos se exercem sempre da minoria para a maioria. O "poder do povo" será necessariamente o que separa o exercício do governo da representação da sociedade.

Dito isso, a representação política aparece, de pleno direito, como forma oligárquica de poder, já que é representação pelas "minorias com título" para se ocupar dos negócios comuns. É a partir do percurso que leva do governo da maioria ao da minoria que se exige uma separação importante entre questões postas sob democracia direta e sob democracia representativa, a última tida como a marca registrada na sociedade moderna.

A evidência que assimila a democracia à forma do governo representativo resultante de eleição é recente na história, mas esse modo representativo é o exato oposto da democracia lá entre os gregos. $\mathrm{O}$ autor declara que, mesmo onde é reconhecida a igualdade dos "homens" e dos "cidadãos", tal igualdade é reconhecida na relação destes com a esfera jurídico-política constituída e, mesmo onde a soberania é popular, só o é na ação de seus governantes e representantes. Tal igualdade faz distinção entre o público, que pertence a todos, e o privado, em que reina a liberdade de cada um, o que levaria à dominação pelos que detêm poderes na sociedade.

Nesse compasso, a democracia caminha para além do âmbito dos indivíduos empenhados em 
sua felicidade privada. Ela é o processo de luta contra a privatização e é o processo de ampliação dessa esfera. Ampliar a esfera pública não significa exigir a intervenção do Estado na sociedade, e sim lutar contra a divisão entre o público e o privado.

O processo democrático, conclui o autor, implica: a ação de sujeitos que reconfiguram as distribuições do privado e do público, do universal e do particular. Esse processo deve trazer de volta o significado da palavra democracia, a rejeição da pretensão dos governos de tornar/encarnar um princípio uno da vida pública, circunscrevendo a compreensão e extensão dessa vida pública. Se existe uma limitação para a democracia, ela reside no movimento que desloca os limites do público e do privado, do político e do social.

\section{Referências bibliográficas}

RANCIÈRE, J. $O$ desentendimento. São Paulo: Editora 34, 1996.

- O ódio à democracia. São

Paulo: Boitempo, 2014. 